\title{
Port Competitiveness Evaluation by Fuzzy Multicriteria Grade Classification Model
}

\author{
Wen-Chih Huang \\ Associate Professor, Dept. of Harbor and River Engineering, National Taiwan Ocean University. Keelung, 202, Taiwan. \\ Junn-Yuan Teng \\ Associate Professor, Dept. of Industrial Management, Huafan University. Shihdin, Taipei, 223, Taiwan. \\ Miin-Jye Huang \\ Doctor Candidate, Dept. of Harbor and River Engineering, National Taiwan Ocean University. Keelung, 202, Taiwan. \\ Ming-Shin Kou \\ Doctor Candidate, Dept. of Harbor and River Engineering, National Taiwan Ocean University. Keelung, 202, Taiwan.
}

Follow this and additional works at: https://jmstt.ntou.edu.tw/journal

Part of the Civil and Environmental Engineering Commons

\section{Recommended Citation}

Huang, Wen-Chih; Teng, Junn-Yuan; Huang, Miin-Jye; and Kou, Ming-Shin (2003) "Port Competitiveness Evaluation by Fuzzy Multicriteria Grade Classification Model," Journal of Marine Science and Technology. Vol. 11: Iss. 1, Article 7. DOI: $10.51400 / 2709-6998.2280$

Available at: https://jmstt.ntou.edu.tw/journal/vol11/iss1/7

This Research Article is brought to you for free and open access by Journal of Marine Science and Technology. It has been accepted for inclusion in Journal of Marine Science and Technology by an authorized editor of Journal of Marine Science and Technology. 


\title{
PORT COMPETITIVENESS EVALUATION BY FUZZY MULTICRITERIA GRADE CLASSIFICATION MODEL
}

\author{
Wen-Chih Huang*, Junn-Yuan Teng**, Miin-Jye Huang***, and Ming-Shin Kou***
}

Key words: port competitiveness, fuzzy, classification model, MCDM.

\section{ABSTRACT}

Competitiveness measurement of ports should be different from business/enterprises of the private sector. It needs to consider operational efficiency and overall effectiveness. Therefore, this paper attempts to establish a multi-criteria evaluation model. We develop Fuzzy Multi-criteria Grade Classification (FMGC) model to serve the purpose. This model is primarily for qualitative analysis, but this study invites quantitative indicators. It concurrently takes efficiency and effectiveness indicators into consideration. FMGC evaluates port competitiveness classification by partial order based on five grades. Partial order is sufficient to present superiority of port competitiveness. This paper takes eight East Asian container seaports for empirical study, also embarks on scenario analysis for Taiwan's three main ports. It confirms the method is stable and effective in practical applications.

\section{INTRODUCTION}

Management of port should be different from a business entity of private sector. Consequently, competitiveness measurement should be different from each other. Port has to consider its own operational efficiency and also overall effectiveness. Nevertheless, the competitiveness definition has not reached consensus. Researches incline to adopt criteria of production efficiency or operational performance. This paper is to investigate the characteristics of port competitiveness and develop Fuzzy Multi-criteria Grade Classification (FMGC) model. The approach is on the merits of simplicity for mathematical operation and questionnaire survey. Evaluation approaches for competitiveness include five categories, data envelopment analysis

Paper Submitted 07/05/02, Accepted 04/16/03. Author for Correspondence: Wen-Chih Huang.

*Associate Professor, Dept. of Harbor and River Engineering, National Taiwan Ocean University. Keelung, 202, Taiwan.

**Associate Professor, Dept. of Industrial Management, Huafan University. Shihdin, Taipei, 223, Taiwan.

***Doctor Candidate, Dept. of Harbor and River Engineering, National Taiwan Ocean University. Keelung, 202, Taiwan.
(DEA), operational competitiveness ratings analysis (OCRA), Game theories, productivity analysis, and multi-criteria decision making (MCDM) methods. DEA and OCRA are of operational efficiency. Game theories emphasize quantity decision under competition environments. Productivity is the efficiency of inputs and outputs. The above methods are of quantitative methods. MCDM encounters quantitative and qualitative information and efficiency and effectiveness indicators. This paper is by way of MCDM to develop a pertinent evaluation approach for port.

The rest of this paper is organized as follows. Part Two investigates the related researches. Part Three puts forward FMGC model. Part Four proceeds to scenario analysis and discussion. Finally, the conclusion remarks of the study.

\section{COMPETITIVENESS MEASUREMENT}

Miyajima and Kwak [15] examined container cargo competition among Japanese ports. Warf and Kleyn [28] investigated the competition of eight major ports of the United States and focused on comparing the loading/unloading volumes and benefits of the ports. Heaver [6] presented the idea of improving competitiveness, but did not carry it further to include evaluation. Chen [3] investigated port competitive advantages by port service, container terminal service, and economic/geographic conditions. Kaohsiung Harbor Bureau [13] applied core competency concept by taking sixty evaluation indicators to analyze its competitiveness. Huang et al. [8, 9] and Huang et al. [11] applied Analytic Hierarchy Process (AHP) and Grey Theory to evaluate competitiveness of East Asian container ports. Papers $[2,4,23,24]$ extended to include production factors or productivity indicators to assess ports productivity. While those papers [7, 21, 25, 26, 27] investigated port performance by meaning of ship, berth or terminal indicators.

There is already significant amount of researches on the topic of business/corporate competitiveness. Prescott and Grant [22] were pioneers by reviewing 
those competitiveness researches and presenting characteristics of twenty-one evaluation approaches. Oral [16] classified analysis approaches in two categories: (1) descriptive approach, and (2) analytical approach. Analytical approach pursued analysis by mathematical algorithm. Oral and et cetera were pioneers in modelbased approach. Oral [16] applied linear programming on strategies and competitiveness evaluation of glass industry. Parkan [19] presented OCRA, and followed by Parkan and $\mathrm{Wu}$ [20] and Jayanthi et al. [12] in their respective researches. Jayanthi also applied DEA to assess the competitiveness of twenty food processing companies. Oral and Dominique [18] adopted Total Factor Productivity (TFP) to structure an analysis model for competitive strategies of business companies. Jayanthi et al. [12] opted to TFP in his research of competition of companies for comparison with OCRA and reached the conclusion that there was not significant interrelation between TFP and OCRA. Oral et al. [17] studied on firm's productivity and competitiveness and concluded that productivity and competitiveness both were highly co-related. Karnani [14] used game theory in the analysis of market dominance under oligopoly competition. Dutta and King [5] used the game theory for assessing competition strategies.

Huang et al. [10] had classified port evaluation indicators into two categories: efficiency and effectiveness. Effectiveness indicators further divided into two groups: (1) cost included, and (2) cost excluded. The group (1) encompassed total cost incurred in a port. The group (2) included congestion, total waiting time in port territory, and ship mean time in port.

Efficiency indicators included ship/berth and container's terminal sub-groups. The former involved average service time duration for a ship, average loading and unloading duration, average waiting time of a vessel, operational efficiency of loading/unloading facilities on board and so on, to measure operational efficiency of ships in a berth. The latter involved efficiency of terminal operation including inland train and truck links, container reclaiming efficiency, terminal landuse efficiency, and container flow circulation capacity. Those indicators were to measure operational efficiency of a container depot /or terminal. In other words, effectiveness indicators presented the extent of achievement of port's overall goals.

Those above-mentioned competitiveness evaluation approaches, i.e., DEA and OCRA, non-parametric approaches by taking input(s) and output(s) as evaluation indicators, are confined to few alternatives in evaluation. Productivity is to evaluate operational efficiency. Game theory by applying linear programming is in essence to processing quantitative data for continuous alternatives. The fifth one, MCDM, can treat both quantitative and qualitative data, and includes a wider range of evaluation indicators including efficiency and effectiveness. In literature, evaluation indicators for ports including competitiveness, and productivity measurement could be classified into efficiency and effectiveness. Effectiveness indicators have more weight than those of efficiency in competitiveness evaluation, approximately $70 \%$ against $30 \%$; but have less weight than efficiency in productivity evaluation (shown Table 1) on an average approximately of $25 \%$ by $75 \%$. In the evaluation of port competitiveness, it may be deemed appropriate to focusing upon effectiveness. Productivity is primarily focusing on efficiency shown on the following Fig. 1, and thereby cannot pertinently measure competitiveness of ports. A framework presented by Brown and Svenson [1] covering inputs, outputs and outcomes is helpful for indicator and approach selection of port competitiveness evaluation.

In this paper, port competitiveness is defined as the ability of a port and its vicinity in the creation of value-added. Port competitiveness evaluation shall take efficiency and effectiveness indices into

Table 1. Efficiency and effectiveness in port evaluation indicators

\begin{tabular}{|c|c|c|c|c|c|c|}
\hline \multirow[t]{2}{*}{ Category } & \multirow[t]{2}{*}{ Literature } & \multirow{2}{*}{$\begin{array}{c}\text { Total No. of } \\
\text { indicators }\end{array}$} & \multicolumn{2}{|c|}{ No. of indicators } & \multicolumn{2}{|c|}{ Percentage $(\%)$} \\
\hline & & & Efficiency & Effectiveness & Efficiency & Effectiveness \\
\hline \multirow[t]{2}{*}{ Port } & Warf and Kleyn (1989) & 2 & 0 & 2 & 0 & 100 \\
\hline & Chen (1997) & 7 & 2 & 5 & 28.6 & 71.4 \\
\hline \multirow[t]{2}{*}{ Competitiveness } & Kaohsiung Harbor (1999) & 60 & 17 & 43 & 28.7 & 71.7 \\
\hline & Huang et al. $(1999 ; 2001 ; 2002)$ & $31 \mathrm{a}$ & 11 & 20 & 28.9 & 71.1 \\
\hline \multirow[t]{2}{*}{ Port } & Chang (1978) & $3 \mathrm{~b}$ & 1 & 2 & 33 & 67 \\
\hline & Dowd and Leschine (1990) & 8 & 8 & 0 & 100 & 0 \\
\hline \multirow[t]{2}{*}{ Productivity } & Sachish (1996) & 37 & 30 & 7 & 81.1 & 18.9 \\
\hline & Robinson (1999) & 6 & 5 & 1 & 83 & 17 \\
\hline
\end{tabular}

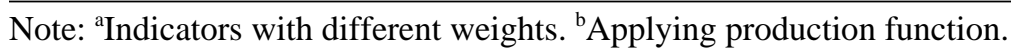


consideration. The analysis of port competitive advantage can be classified into full order and partial order two types. Some distinguished researches opt to cluster analysis, while others use full order. In fact, full order ranking for comparing the improvement of port competitiveness is not necessarily pertinent to decisionmakers, if port's ranking varies by marginal difference. On the other hand, the partial order grading provides sufficient information for decision-makers. This research embarks on a MCDM method on the ground of rating simplicity and few interviewees needed. It is also considering fuzzy feature of indicators and simple calculation.

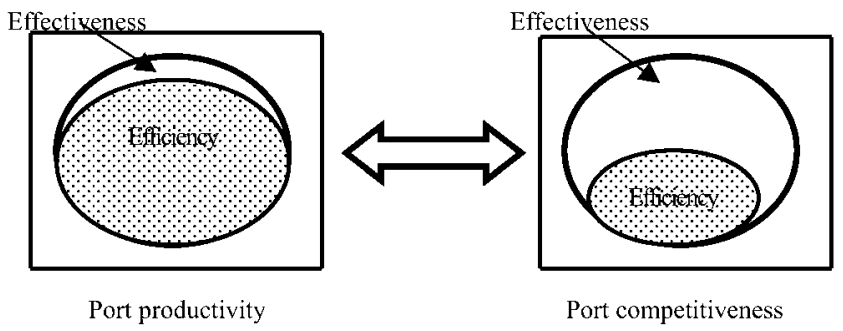

Fig.1. Comparison of port competitiveness and productivity by difference of effectiveness and efficiency.

\section{METHODOLOGY}

On the partial order grading, this research is by FMGC model with tangible and intangible indicators for evaluating competitiveness of container ports. It is given that there are $n$ number of competitive container ports $A=\left(a_{1}, \ldots, a_{i}, \ldots, a_{n}\right)(n \geq 1)$. Under $m$ number of evaluation criteria, then $C=\left(c_{1}, \ldots, c_{j}, \ldots, c_{m}\right)(m \geq 1)$, divide each criteria based on performance achievement into $p$ number of grades $V_{j}=\left(v_{j 1}, \ldots, v_{j k}, \ldots, v_{j p}\right)(p \geq 2)$. Also, each grade will be reset in an order of its distinguished qualities, i.e., $v_{j 1}$ implies the most priority; $v_{j p}$ means relatively the least priority. Experts in relevant areas can provide different weights on the significance for each of $m$ number of criteria $W=\left(w_{1}, \ldots, w_{j}, \ldots, w_{m}\right)$. Based on decision and measurements provided by experts, the establishment of the fuzzy evaluation matrix $\widetilde{\boldsymbol{R}}$ of each port $a_{i}$ under evaluation criterion $c_{j}$ is as the following:

$$
\tilde{\boldsymbol{R}}=\left[\tilde{r}_{i j k}\right]_{m \times p}, \quad i=1,2, \ldots, n
$$

Where, $\tilde{r}_{i j k}$ indicates the fuzzy performance of $a_{i}$ port at $v_{j k}$ grade based on $c_{j}$ criterion. Although the evaluation criterion of a port has a qualitative nature, it can also be a quantifiable criterion. It is appropriate to have 5 to 9 experts to conclude the grade classification on each criterion. Assuming there are $q$ experts, fuzzy performance $\tilde{r}_{i j k}$ for each port under each criterion of grade classification can be obtained as the following:

$$
\begin{aligned}
& \tilde{r}_{i j k}=Q_{i j k} / q, \quad \forall i, j, k \\
& Q_{i j k}=\sum_{f=1}^{q} Q_{i j k}^{f}, \quad \forall i, j, k \\
& Q_{i j k}^{f}=\left\{\begin{array}{c}
1, \text { if experts consider } a_{i} \text { port } \\
\text { as } k \text { grade of } c_{j} \text { criterion. } \\
0, \text { others. }
\end{array}\right. \\
& \sum_{k=1}^{p} Q_{i j k}=q \\
& 0 \leq \tilde{r}_{i j k} \leq 1
\end{aligned}
$$

When considering $m$ number of evaluation criteria, a weighted fuzzy evaluation vector $\tilde{\boldsymbol{e}}_{\boldsymbol{i}}$ is obtained as:

$$
\begin{aligned}
& \tilde{\boldsymbol{e}}_{i}=\left(e_{i l}, \cdots, e_{i k}, \cdots, e_{i p}\right)=W \otimes \tilde{\boldsymbol{R}} \\
& e_{i k}=\sum_{j=1}^{m} w_{j} \tilde{r}_{i j k}, \quad k=1,2, \ldots, p \\
& \sum_{k=1}^{p} e_{i k} \quad i=1,2, \ldots, n
\end{aligned}
$$

$e_{i k}$ refers to container port $a_{i}$, under $m$ number of evaluation criteria, has been evaluated as the degree of membership under No. $k$ grade. Thus, the order of priority for the project under certain $\left(e_{i 1}, e_{i 2}, \ldots, e_{i p}\right)$ conditions is established by conducting a grade classification on $n$ number of ports $a_{1}, a_{2}, \ldots, a_{n}$. If one criterion is quantifiable, all data of those ports can be collected and compared. The evaluation criterion is crisp instead of fuzzy. We divide those ports into $p$ grades by $p$ equal intervals between maximal and minimal statistical values. In this case, $r_{i j k}=Q_{i j k}=1$, each port falls under one certain grade $k$ according to its value.

In the grade classification, it is assumed that only 2 grades shall be conducted (i.e., $p=2) V=(x, y)$. As long as the degree of membership belonging to $x$ grade has reached a certain $\theta$ value, then $a_{i}$ shall fall under $x$. ( $\theta$ value can be decided by experts, e.g., $\theta=0.5,0.7$, and so on). On the other hand, if $a_{i}$ falls under $y$, assuming and $\alpha_{y}$ represent the degree of membership of $a_{i} \in x, a_{i}$ $\in y$, and $\alpha_{x}+\alpha_{y}=1$, then three conditions will occur: (1) if $\alpha_{x}>\theta$, then $a_{i} \in x$, (2) if $\alpha_{x}=\theta$, then $a_{i} \in x$ or $a_{i} \in y$, (3) if $\alpha_{y}>\theta$, then $a_{i} \in y$. If the grade classification is divided into $3(p=3) V=(x, y, z)$. The grade classification evaluation of port $a_{i}$ can be based on two grade components $V_{1}=(x, y$ or $z)$ and $V_{2}=(y, z)$. At the same time, it can provide the degrees of membership for $\left(\alpha_{1}, \bar{\alpha}_{1}\right)$ and $\left(\alpha_{2}, \bar{\alpha}_{2}\right)$. Also, $\alpha_{1}+\bar{\alpha}_{1}=1, \alpha_{2}+\bar{\alpha}_{2}=1$. 
Based on the values $\alpha_{1}$ and $\alpha_{2}$, we can conduct a grade classification, i.e.,

(1) if $\alpha_{1} \geq \theta$, then $a_{i} \in x$

(2) if $\bar{\alpha}_{1} \geq \theta$, then $a_{i} \in y$ or $a_{i} \in z$ then decided on value $\alpha_{2}$

(a) if $\alpha_{2} \geq \theta$, then $a_{i} \in y$

(b) if $\bar{\alpha}_{2} \geq \theta$, then $a_{i} \in z$

Thus, with respect to $p$, the number of valuation grades, $V=\left(v_{1}, v_{2}, \ldots, v_{p}\right)(p \geq 2)$, can be structured into $(p-1)$ number of evaluation sets from 2 neighboring grades, i.e.,

$$
\begin{aligned}
& \mathbf{v}_{1}=\left(v_{1}, v_{2} \text { or } v_{3} \text { or } v_{4} \text { or } \ldots \text { or } v_{p}\right) \\
& \mathbf{v}_{2}=\left(v_{2} \text { or } v_{3} \text { or } \ldots \text { or } v_{p}\right) \\
& \ldots \\
& \mathbf{v}_{\mathbf{p}-\mathbf{1}}=\left(v_{p-1}, v_{p}\right)
\end{aligned}
$$

If evaluating the same port $a_{i}$ is conducted in accordance with $\mathbf{v}_{\mathbf{1}}, \mathbf{v}^{\prime}{ }_{\mathbf{2}}, \ldots, \mathbf{v}_{\mathbf{p}-\mathbf{1}}$, a corresponding degree of membership $\alpha_{1}, \alpha_{2}, \ldots, \alpha_{p-1}$ can be obtained. Then, based on the following rule, a grade classification can be conducted:

1. if $\alpha_{1} \geq \theta$, then $a_{i} \in v_{1}$; otherwise

2. if $\alpha_{2} \geq \theta$, then $a_{i} \in v_{2}$; otherwise

$$
(p-1) \text {. If } \alpha_{p-1} \geq \theta \text {, then } a_{i} \in v_{p-1} \text {; }
$$$$
\text { otherwise } a_{i} \in v_{p}
$$

From the above logical deduction process, it obtains that if the degree of membership $\alpha_{1}, \alpha_{2}, \ldots, \alpha_{p-1}$ can be found, then problems with the above-mentioned grade classification can be solved. This study applies accumulation to obtain each grade classification evaluation's degree of membership, i.e.,

$$
\begin{aligned}
& \alpha_{1}=e_{i 1}=\sum_{k=1}^{1} e_{i k} \\
& \alpha_{2}=\alpha_{1}+e_{i 2}=\sum_{k=1}^{2} e_{i k} \\
& \alpha_{3}=\alpha_{2}+e_{i 3}=\sum_{k=1}^{3} e_{i k}
\end{aligned}
$$

$$
\begin{aligned}
& \alpha_{p-1}=\alpha_{p-2}+e_{i(p-1)}=\sum_{k=1}^{p-1} e_{i k} \\
& \alpha_{p}=\sum_{k=1}^{p} e_{i k}
\end{aligned}
$$

From those of the above, the respective $\left(\alpha_{1}, \alpha_{2}, \ldots\right.$, $\left.\alpha_{p}\right)$ is actual degree of membership for the port $a_{i}$, which has been evaluated as No. $1,2, \ldots ., p$ grade. The following equation can be used to illustrate this:

$$
\begin{aligned}
& e_{I \Sigma}=\left(\alpha_{1}, \alpha_{2}, \ldots, \alpha_{p}\right) \\
& =\left(\sum_{k=1}^{1} e_{i k}, \sum_{k=1}^{2} e_{i k}, \ldots, \sum_{k=1}^{p} e_{i k}\right)
\end{aligned}
$$

To classify the grade of each of those ports, it is based on the above degree of membership for each grade evaluation set and the $\theta$ values decided by questionnaire, i.e.,

$$
\begin{aligned}
& \text { If } \alpha_{i d} \geq \theta \text {, then } a_{i} \in v_{d}, \forall i, k \\
& \text { of which } d=\min \left(k \mid \alpha_{i k} \geq \theta\right)
\end{aligned}
$$

If the degree of membership is greater then $\theta$, the alternative $a_{i}$ falls in the minimal grade $k$, defined as $d$.

The FMGC method can present those ports under evaluation into five grades, or into the number of the researcher's needs. Grades' classification is set up according to questionnaire survey scoring. For example, if performance scorings are classified into three grades, the best alternative may fall in the grade three, the grade four, or the grade five via FMGC. In this case, the best one resides at the grade three or moderate degree. The FMGC provides decision-maker with definitely fivegrade grouping information. It is simple to fill in the questionnaire survey, especially suitable for intangible indicators. To verify the usability, rationality and efficiency of FMGC, it is to take a descending stanza for eight East Asian container ports.

\section{EMPIRICAL STUDY}

The main East Asian container ports ranked in the category of world major twenty-five, totaling fifty percent of global TEU volume. In this paper container ports brought for study are Singapore, Kobe, Pusan, Hong Kong, Shanghai, Kaohsiung, Taichung and Keelung. In the year of 2001, container loading/unloading volume were: Hong Kong 17.9 million TEUs, Singapore 15.6 million TEUs, Kobe 2.1 million TEUs, Pusan 7.9 million TEUs, Shanghai 6.3 million TEUs, Kaohsiung 7.5 million TEUs, Taichung Port 1.1 million TEUs, Keelung 1.8 million TEUs. The annual growth rate exceeding of $10 \%$ are Pusan, Shanghai, and Taichung 
Port. The annual growth rate exceeds $6 \%$ are Hong Kong and Singapore. Kaohsiung is between 4.1 4.7\%. Keelung is recorded with a rate of $-4.0 \%$ between 1994 and 2000, excluding the volume of its supplement ports.

The following major projects respectively are undertaken by the ports' authorities to enhance their competitiveness. Hong Kong: No. 9 container terminal project, dredging Kwai Chung terminal's major channel, Tuen Mun inner-river container wharf, and Lantau new port plan. Singapore: Promotion of oversea investment, Pasir Panjang Container Terminal Project. Shanghai: Yangtze River dredging project. Kobe: Port Island 2nd Phase Project, Rokko Island South Project, and New Kobe International Airport. Pusan: Gamman wharf extension project. Kaohsiung's No. 5 Container Terminal is completed, and Outer Harbor Extension Project is in the evaluation stage. Keelung Port's software improvement program is under review. Keelung Port's supplemental port is under its first phase construction. The first container terminal, seven berths, will be in operation in 2005. Taichung Port is on its second phase extension projects.

In order to assess the competitiveness of those above container ports, those evaluation indicators from Huang et al. [8,9] and relevant studies have been investigated. This paper concludes thirty-one indicators. Amongst the total thirty-one, eleven are of efficiency indicators (earmarked by $*$ ), the remaining twenty are of effectiveness. Those indicators are (1) Labor quality*,

(2) Customs service impact, (3) Operational efficiency*, (4) Liberalization of operation *, (5) Operation cost of carriers, (6) Port services charge, (7) Ship mean time in port, (8) Machinery loading/unloading efficiency*, (9) Container terminal movement capability*, (10) Port location, (11) Sailing points, (12) Schedule, (13) Inbound / out-bound container, (14) Number and ratio of transshipment containers, (15) Rail/ highway transport, (16) Waterway transport, (17) Number of deep-draft wharves*, (18) Number of operational machinery *,
(19) Operational land for container terminals*, (20) Container automation*, (21) EDI*, (22) Shipping information*, (23) Land of warehouse / logistics, (24) Investment plan, (25) Investors of wharves, (26) Operator, (27) Political stability, (28) Social stability, (29) Hinterland productivity, (30) Economical stability, (31) Financial liberalization.

Although there are fourteen applicable tangible data; nevertheless, not all of the fourteen criteria are available to those eight container ports. Consequently, in this study except six tangible indicators, the other intangible criteria are provided by the expert survey rating from 1 to 5 . The model applies the same questionnaire data resulted from the previous study for comparison against the AHP method.

Values accumulation of membership for eight study cases calculated through formulas of the third part are listed on Table 2 . Those five grades, $v_{1} \sim v_{5}$, are: excellent, high, moderate, average, and poor. A comparison of the value $\theta$ standing at 0.5 from this study against the outcomes by the AHP method, Grey Relational Analysis (GRA) [9], and Cluster Analysis are illustrated on Table 3. These ports are separated into three groups by three equal intervals between the highest and the lowest rating of AHP. They are Singapore, Hong Kong classified in group 1 or Hub Port; Kobe, Kaohsiung are in group 2 or Side Port, and Pusan, Shanghai, Keelung and Taichung in group 3 or Feeder Port.

The result of grouping by FMGC at $\theta=0.5$, there are only two ports in different grade against the result of Cluster Analysis using twenty indicators with factor loading greater than 0.75 by Ward method. It is the same as the AHP. FMGC and the AHP take indicator's weight into consideration, but Cluster Analysis doesn't. The outcomes via Cluster Analysis are more variance than FMGC and AHP. The outcome via Cluster Analysis using 31 indicators is of two clusters. The result of FMGC grouping is more reasonable than those three groups out of AHP method. The group 1, 2, and 3 in this

Table 2. Accumulation membership of eight major container ports

\begin{tabular}{|c|c|c|c|c|c|}
\hline Ports & Grades $\quad\left(v_{1}\right)$ & $\left(v_{2}\right)$ & $\left(v_{3}\right)$ & $\left(v_{4}\right)$ & $\left(v_{5}\right)$ \\
\hline Keelung & 0.0956 & 0.4539 & 0.7076 & 0.8645 & 0.9980 \\
\hline Taichung & 0.0781 & 0.4900 & 0.7557 & 0.9019 & 0.9990 \\
\hline Kaohsiung & 0.2538 & 0.6899 & 0.8639 & 0.9747 & 0.9980 \\
\hline Hong Kong & 0.5242 & 0.7862 & 0.9081 & 0.9756 & 0.9980 \\
\hline Shanghai & 0.1087 & 0.3091 & 0.6538 & 0.8532 & 0.9980 \\
\hline Pusan & 0.0537 & 0.4115 & 0.7389 & 0.9342 & 0.9980 \\
\hline Kobe & 0.2741 & 0.6308 & 0.8262 & 0.9158 & 0.9892 \\
\hline Singapore & 0.7093 & 0.8949 & 0.9518 & 0.9819 & 0.9897 \\
\hline
\end{tabular}


Table 3. Comparing orders of eight major container ports

\begin{tabular}{lccccccccl}
\hline Ports & Keelung & Taichung & Kaohsiung & Hong Kong & Shanghai & Pusan & Kobe & Singapore & \\
\hline Grades & III & III & II & I & III & III & II & I & AHP [8] \\
Order & 7 & 5 & 3 & 2 & 8 & 6 & 4 & 1 & AHP [8] \\
Order & 8 & 6 & 3 & 2 & 7 & 5 & 4 & 1 & GRA [9] \\
Grades & III & III & II & I & III & III & II & I & FMGC, $\theta=0.5$ \\
Grades & III & III & II & I & II & II & II & I & Cluster Analysis \\
\hline
\end{tabular}

Note: Cluster Analysis uses twenty criteria with factor loading greater than 0.75 .

Table 4. Accumulation membership for condition one

\begin{tabular}{|c|c|c|c|c|c|}
\hline Ports & Grades & $\left(v_{2}\right)$ & $\left(v_{3}\right)$ & $\left(v_{4}\right)$ & $\left(v_{5}\right)$ \\
\hline Keelung & 0.0198 & 0.3261 & 0.6604 & 0.8517 & 0.9980 \\
\hline Taichung & 0.0219 & 0.3499 & 0.7184 & 0.8880 & 0.9980 \\
\hline Kaohsiung & 0.1760 & 0.5271 & 0.8692 & 0.9622 & 0.9978 \\
\hline Hong Kong & 0.5242 & 0.7862 & 0.9081 & 0.9756 & 0.9980 \\
\hline Shanghai & 0.2355 & 0.5162 & 0.8208 & 0.9317 & 0.9981 \\
\hline Pusan & 0.1624 & 0.5509 & 0.8252 & 0.9525 & 0.9980 \\
\hline Kobe & 0.2741 & 0.6308 & 0.8262 & 0.9158 & 0.9892 \\
\hline Singapore & 0.7093 & 0.8949 & 0.9518 & 0.9819 & 0.9897 \\
\hline
\end{tabular}

example are $v_{1}, v_{2}, v_{3}$ via FMGC respectively. The $v_{3}$ implies moderate grade. FMGC model is an excellent analysis tool for grade classification research.

\section{SCENARIO ANALYSIS AND DISSCUSION}

The scenario analysis is proceeded under the following two hypotheses.

1. First, Taiwan's political, social, economical environments were deteriorating in the next five years. Grades $v_{i}$ of social, political and economical stability, as indicators $27,28,29,30$ were respectively downgraded by one grade. On the contrary, politic and economy are stable in China and Korea, $v_{i}$ of the indicators $5,6,27,28,30,31$ were upgraded by one grade. Shanghai's port facilities keep rising and indicators 7 , 8,9 upgrade one grade, Other quantitative indicators $13,14,17,18,19$ of the year of 2001 were renewed duly. Index of geographical location is unchangeable. The outcome indicates that Singapore and Hong Kong are in the first grade, Pusan, Kaohsiung, Kobe, and Shanghai in the second grade, Keelung and Taichung Port in the third. Pusan's competitiveness has exceeded Kaohsiung. Shanghai stands at the level close to Kaohsiung. Both Keelung and Taichung Port are far behind them in the next years (Shown Table 4).

2. Second, Labor quality, customs service, operation cost, and service charge (indicators 1, 2, 5,6) of
Taiwan's three major ports will be improved. Those indicators should be upgraded by one grade. Indicators $27,29,30,31$ will be promoted to reach the level of Hong Kong. Quantitative indicators 13, 14 of Kaohsiung became grade $v_{1}$, its loading volume is near 15 millions TEU per year, and indicators 8, 9 upgraded one position when its Outer Harbor Project completed.

The outcome by the model indicates Singapore, Kaohsiung and Hong Kong are in the first grade, Kobe, Pusan, Shanghai, Keelung and Taichung Port in the second grade (Shown Table 5). By the accumulation membership values, the Taiwanese competitive port in the first grade is Kaohsiung. Competitiveness of Kaohsiung stands at the level immediately close to Hong Kong. Keelung and Taichung Port's competitiveness are upgraded to the second grade.

FMGC model can effectively operate when evaluation indicators have been changed. The model invites tangible data into evaluation in cases some data are not continuously available. It can retreat more evaluation subjects than its original function of fuzzy evaluation criteria. In scenario analysis, change of grade for each respective port will not be sensitive adequately for evaluation indicators reaching thirty-one. Therefore, reducing indicator and changing indicators with high weights are effective ways to deal with. In order to reduce number of indicators, evaluation indicators shall be sifted. This shall be a topic for further research. 
Table 5. Accumulation membership for condition two

\begin{tabular}{lccccc}
\hline \multicolumn{1}{c}{ Grades } & $\left(v_{1}\right)$ & $\left(v_{2}\right)$ & $\left(v_{3}\right)$ & $\left(v_{4}\right)$ & $\left(v_{5}\right)$ \\
Ports & & & & & \\
\hline Keelung & 0.2763 & $\mathbf{0 . 5 3 1 0}$ & 0.7453 & 0.8458 & 0.9980 \\
Taichung & 0.2590 & $\mathbf{0 . 5 8 2 9}$ & 0.7819 & 0.9072 & 0.9980 \\
Kaohsiung & $\mathbf{0 . 5 2 6 1}$ & 0.8105 & 0.9104 & 0.9817 & 0.9998 \\
Hong Kong & $\mathbf{0 . 5 2 4 2}$ & 0.7862 & 0.9081 & 0.9756 & 0.9980 \\
Shanghai & 0.2355 & $\mathbf{0 . 5 1 6 2}$ & 0.8208 & 0.9317 & 0.9981 \\
Pusan & 0.1624 & $\mathbf{0 . 5 5 0 9}$ & 0.8252 & 0.9525 & 0.9980 \\
Kobe & 0.2741 & $\mathbf{0 . 6 3 0 8}$ & 0.8262 & 0.9158 & 0.9892 \\
Singapore & $\mathbf{0 . 7 0 9 3}$ & 0.8949 & 0.9518 & 0.9819 & 0.9897 \\
\hline
\end{tabular}

\section{CONCLUSIONS}

Among five categories of competitiveness evaluation methods, i.e., OCRA, DEA, Game theories, Productivity analysis, and MCDM, it is the MCDM that can effectively take a comparatively wider range of indicators into consideration, including efficiency and effectiveness indicators. This paper selected FMGC method to evaluate port competitiveness. The evaluation results of port competitiveness by FMGC proves that $\theta=$ 0.5 , Singapore and Hong Kong are ranked as the grade 1, Kaohsiung and Kobe as the grade 2, Pusan, Shanghai, Keelung Port, and Taichung Port as the grade 3 . The grade 1, 2, 3 via FMGC is $v_{1}, v_{2}, v_{3}$ respectively. The result is more reasonable than three grades of AHP method.

Indicators of effectiveness have more weight than efficiency in competitiveness evaluation. By and large, effectiveness has less weight in productivity evaluation.

International trade has been getting more significance in the light of emergence of global village and sustainable development. Port is the predominant contributor to facilitate international trade. Study of competitiveness comparison may assist authorities of concern to improve management, development strategies including the surrounding environment deemed appropriate to each respective port. Kaohsiung Port has the advantages of greater production hinterland and adequate space of water and land in the port for expansion development. It is most likely to be upgraded into the group one ports, i.e., a hub harbor for global logistics management. However, substantial effort to repositioning both policy and strategy is needed. Keelung and Taichung Port will be in the second group by improving their labor quality, customs service, container automation, EDI, and ship information, social, political, and economical stability. Keelung Port has to renovate those existing wharves to transform into a passenger and cargo port.

\section{REFERENCES}

1. Brown, M.G. and Svenson, R.A., "Measuring R\&D Productivity," Research Technology Management, Vol. 31, No. 4, pp. 11-15 (1988).

2. Chang, S., "Production Function, Productivities, and Capacity Utilization of Port of Mobil," Maritime Policy and Management, Vol. 5, No. 3, pp. 297-305 (1978).

3. Chen, T., "Competitive Advantages of Container Ports," Transportation Planning Journal, Taipei, Taiwan, Vol. 16, No. 3, pp. 449-472 (1997).

4. Dowd, T.J. and Leschine, T.M., "Container Terminal Productivity: A Perspective," Maritime Policy and Management, Vol. 17, No. 2, pp. 125-133 (1990).

5. Dutta, B.K. and King, W.R., "A Competitive Scenario Modeling System," Management Science, Vol. 26, No. 3, pp. 261-273 (1980).

6. Heaver, T.D., "The Implications of Increased Competition among Ports for Policy and Management," Maritime Policy and Management, Vol. 22, No. 2, pp. 125133 (1995).

7. Hoffman, P., "Performance Indicators and Productivity," Port Management Textbook Containerization, Bremen (1985).

8. Huang, M.-J., Huang, W.-C., Teng, J.-Y., and Wu, S.-C., "Ports Competitiveness Evaluation- Case Study of Eastern Asian Container Ports," Proceedings of Eastern Asia Society for Transportation Studies, Hanoi (2001).

9. Huang, M.-J., Huang, W.-C., Teng, J.-Y., and Wu, S.-C., "Competitiveness Evaluation for Eastern Asian Container Ports by Using Grey Relational Analysis method," The Journal of Grey System, Vol. 14, No. 3, pp. 239-250 (2002).

10. Huang, W.-C., Chen, K.-L., and Chien, C.-W., "Evaluation Indices of Port Transportation System." Proceedings of 11th Academic Seminar, Chinese Institute of Transportation, Taipei, Taiwan (1997). (in Chinese)

11. Huang, W.-C., Teng, J.-Y., Huang, M.-J., and Wu, S.-C., "Integration of the AHP and SWOT Analysis for Port 
Competition Evaluation in the Eastern Asian Region," Proceedings of the Fifth International Symposium on the Analytic Hierarchy Process, Kobe, Japan (1999).

12. Jayanthi, S., Kocha, B., and Sinha, K.K., "Competitive Analysis of Manufacturing Plant: An application to the US Processed Food Industry," European Journal of Operational Research, Vol. 118, No. 2, pp. 217-234 (1999).

13. Kaohsiung Harbor Bureau, “Taiwan's Major International Ports Competitiveness Analysis and Core Competence Model Structuring Project-Kaohsiung Harbor," Kaohsiung, Taiwan (1999). (Press in Chinese )

14. Karnani, A., "Strategic Implications of Market Share Attraction Models," Management Science, Vol. 30, No. 5, pp. 536-547 (1984).

15. Miyajima, M. and Kwak, K.S., "Interport Competition in Container Cargo," Maritime Policy and Management, Vol. 16, No. 1, pp. 47-55 (1989).

16. Oral, M., "A Methodology for Competitiveness Analysis and Strategy Formulation in Glass Industry," European Journal of Operational Research, Vol. 68, No. 1, pp. 9-22 (1993).

17. Oral, M., Cinar, U., and Chabchoub, H., "Linking Industrial Competitiveness and Productivity at the Firm Level," European Journal of Operational Research, Vol. 118, No. 2, pp. 271-277 (1999).

18. Oral, M. and Dominique, C.R., "An Analytical Approach to Competitive Strategy Formulation in Mature Industries," IIE Transactions, Vol. 21, No. 3, pp. 271278 (1989).

19. Parkan, C., "Operational Competitiveness Ratings of
Production Units," Managerial and Decision Economics, Vol. 15, No. 3, pp. 201-221 (1994).

20. Parkan, C. and Wu, M.-L., "Measuring the Performance of Operations of Hong Kong's Manufacturing Industries," European Journal of Operational Research, Vol. 118, No. 2, pp. 235-258 (1999).

21. Plumlee, C.H., "Port Performance Index," Public Works Consultants, 188W Elfin Green, Port Hueneme, California (1979).

22. Prescott, J.E. and Grant, J.H., “A Manager's Guide for Evaluating Competitive Analysis Techniques," Interfaces, Vol. 18, No. 3, pp. 10-22 (1988).

23. Robinson, D., "Measurement of Port Productivity and Container Terminal Design, A Cargo System Report," IIR Publications, London (1999).

24. Sachish, A., "Productivity Functions As a Managerial Tool in Israeli Ports," Maritime Policy and Management, Vol. 23, No. 4, pp. 341-369 (1996).

25. Thomas, B.J., "Operations Planning in Ports," Department of Maritime Studies, Institute of Science and Technology, University of Wales, Cardiff, UK (1985).

26. Tongzon, J.L., "Determinants of Port Performance and Efficiency," Transportation Research A, Vol. 29A, No. 3, pp. 245-252 (1995).

27. UNCTAD, "Port Performance Indicators, United Nations Conference on Trade and Development," Geneva (1976).

28. Warf, B. and Kleyn, L., "Competitive Status of US Ports in the Mid-1980s," Maritime Policy and Management, Vol. 16, No. 2, pp. 157-172 (1989). 